\title{
Explosion-proof thermal type gas flow sensor structure analysis and sensor module development
}

\author{
Gwan-Hyung Kim, Hea-Sung Jung, In-Ho Jung \\ Dept. of Computer Engineering, Tongmyong University, Busan, 608-711, Korea \\ Sam Hoi Industrial.co., LTD, 48-2, 66-BeonGil, Golden Root-ro juchon Myeon, Cimhae-city Gyeongnam, Korea.
}

\begin{tabular}{|c|c|}
\hline Article Info & ABSTRACT \\
\hline Article history: & \multirow{10}{*}{$\begin{array}{l}\text { The present study studied structure analysis and sensor modules for } \\
\text { explosion-proof thermal type flow sensors that can withstand the poor } \\
\text { surroundings of vessel engines and power plants and can be installed in gas } \\
\text { lines. The structure analysis evaluated the integrity of the structures of the } \\
\text { explosion-proof thermal type flow sensors with finite element analysis, and } \\
\text { with regard to the operation of the sensor modules, those sensor modules that } \\
\text { can detect environments where vibrations occur or where there are flows of } \\
\text { high pressure gases or fluids were researched and developed. The explosion- } \\
\text { proof thermal type flow sensor module consists of a sensing part, an } \\
\text { adjustment part, and an output part, and a noise prevention circuit was added } \\
\text { to secure the stability of the measurement signals. The flow sensor developed } \\
\text { with the present study is a sensor module capable of measuring flows in } \\
\text { domestic gas engines and gas piping and it is presented as a reliable sensor } \\
\text { module because it is strong against vibrations and has excellent explosion- } \\
\text { proof performance. }\end{array}$} \\
\hline Received Jun 1, 2018 & \\
\hline Revised Jul 10, 2018 & \\
\hline Accepted Jul 25, 2018 & \\
\hline Keywords: & \\
\hline Finite element analysis & \\
\hline Flow sensor & \\
\hline Gas & \\
\hline Pressure & \\
\hline Vibration & \\
\hline
\end{tabular}

Copyright @ 2019 Institute of Advanced Engineering and Science. All rights reserved.

\section{Corresponding Author:}

Gwan-Hyung Kim,

Department of Computer Engineering,

Tongmyong University,

Busan, 608-711, Korea.

Email: taichiboy1@gmail.com

\section{INTRODUCTION}

Following the strengthening of air pollution standards for large vessels and fossil fuel power plants (thermal) (TIER 3 came into effect in 2016), they were gradually converted into large vessels that use natural gas, which is clean green energy, and combined cycle power plants that use natural gas and other fuels[1-3]. In addition, to prevent the safety problems of nuclear power generation and air pollution due to NOx and fine dust, hereafter, power plants that mainly use gases as fuel will be constructed as additional ones or those that will replace deteriorated ones. Most of the sensor modules currently in use that can measure the flow states of marine vessel engine lines or gas piping lines in power plants are foreign products, and domestic products cannot be easily introduced into the field because they have problems in performance and reliability. In the case of sensors applied to marine vessel engine piping, the severe vibrations of vessels lead to the occurrence of many errors, shortening of lifespans, and frequent occurrence of failure. There are difficulties in the development of such flow sensors because they should strictly satisfy explosion-proof standards and engine vibration conditions because they should be installed in the gas fuel lines of vessels or power plants in special cases [4-7].

The purpose of the present study is to develop flow sensors applicable to vessels or power plants to localize import-dependent products, review the feasibility of explosion-proof thermal flow sensors applicable to gas piping lines with structural analysis, and develop explosion-proof thermal flow sensor modules that can measure the flows of fluids and gases. 


\section{FLOW SENSOR MODELING AND STRUCTURAL ANALYSIS}

In the modeling of an explosion-proof design, the housing was designed to satisfy the explosionproof conditions and cover screws and cable entry screws were designed with specifications that were selected to satisfy explosion-proof conditions[8-9]. The probe was designed so that an element that can measure temperature can be installed. An explosion-proof thermal type gas flow sensor with such a structure is presented in Figure 1.

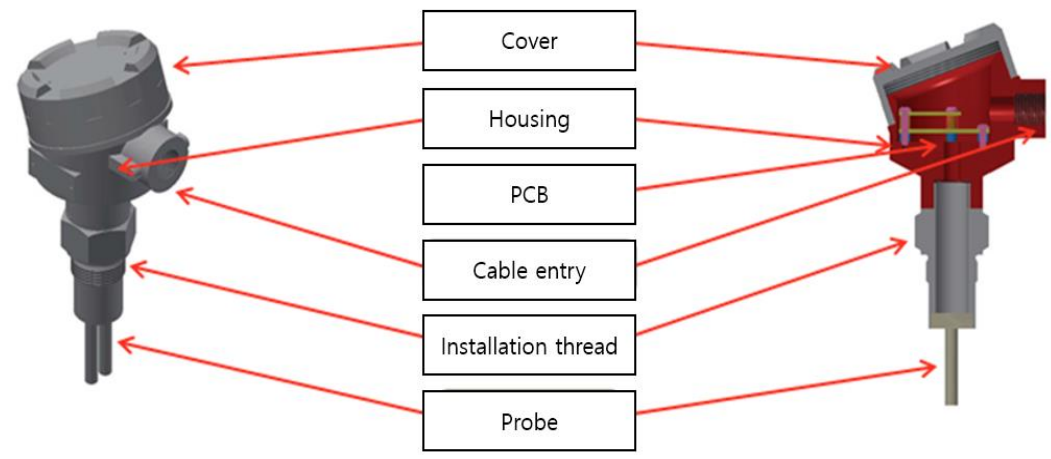

Figure 1. Diagram of thermal type gas flow sensor

In the flow sensor modeling applied to the present study, parameters were selected to fit vessel engines where vibrations occur and high temperature, high pressure power plant environments, and structure analyses were conducted. The flow analysis is aimed at reviewing flow characteristics when one explosionproof thermal type gas flow sensor is attached to a 2" pipe. The flow analysis was conducted using ANSYS V17.0. For analysis of flows in pipes, the flow area was designed to include an area at least five times the diameter in length at the inlet through which fluids flow in and an area at least 10 times the diameter in length at the outlet, because a distance sufficient to show the shape of fully developed fluid flows should be secured in the case of the inlet and a distance sufficient to prevent circulating flows or backflows from reentering at the outlet boundary to affect the numerical calculation should be secured in the case of the outlet, as the flows that have become extremely unstable while passing the body area are stabilized at the outlet. Thermal type gas flow sensor modeling shown in Figure 2.

In the present study, the efficiency of calculation was enhanced by concentrating grids in the body area, where the flow pattern was shown to be extremely turbulent flows, among analysis areas, and by distributing relatively fewer grids in the inlet and outlet areas. Pressures were measured at the inlet and outlet of the strainer and the average values were used. Finally, differential pressures were measured at two points at the inlet of the filter and at six points at the outlet of the filter to review the characteristics of differential pressures for the inlet and outlet.

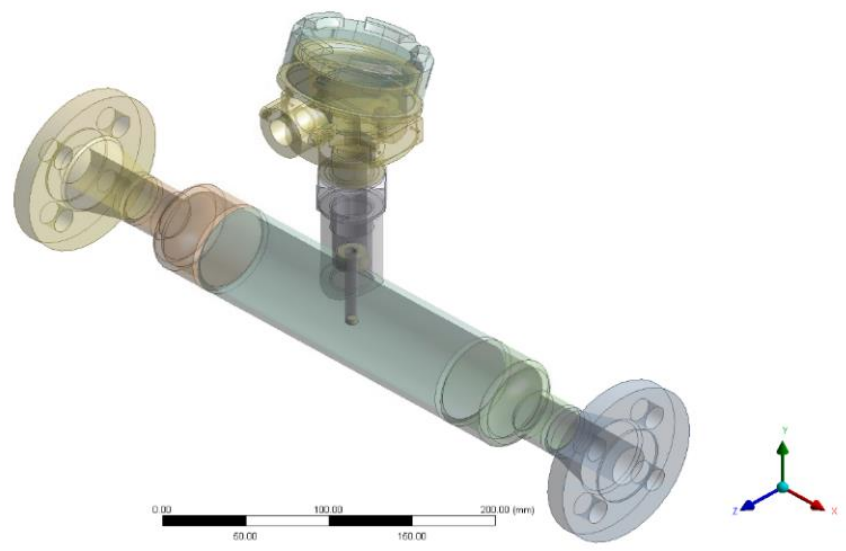

Figure 2. Thermal type gas flow sensor modeling 
The structural analyses of the mechanical properties of materials were limited to aluminum alloy, stainless steel, and PCB among the applied materials considering the physical properties of the materials. The main materials that constitute the explosion-proof thermal type flow sensor are aluminum alloy for die castings, stainless steel, and PCB. Table 1 shows the mechanical properties of individual materials applied to the review of the structural integrity of the flow sensor.

Table 1. Mechanical properties of materials

\begin{tabular}{cccccc}
\hline Material & Applicable Parts & Density & Modulus of elasticity & Poisson's ratio & Yield Strength \\
\hline STS304 & Sensor body & $7,750 \mathrm{~kg} / \mathrm{m} 3$ & $195 \mathrm{GPa}$ & 0.30 & $205 \mathrm{MPa}$ \\
STS316 & Pipe & $7,750 \mathrm{~kg} / \mathrm{m} 3$ & $195 \mathrm{GPa}$ & 0.30 & $205 \mathrm{MPa}$ \\
ALDC & Housing cover/Body & $2,770 \mathrm{~kg} / \mathrm{m} 3$ & $70 \mathrm{MPa}$ & 0.33 & $145 \mathrm{MPa}$ \\
PCB & PCB & $1,890 \mathrm{~kg} / \mathrm{m} 3$ & $13 \mathrm{GPa}$ & 0.30 & - \\
\hline
\end{tabular}

Among the boundary conditions, the inlet condition was set to the static pressure when analyses were conducted considering the characteristics of the flow sensor and assuming the harshest environment, although the flow velocity of the fluids that pass through the pipe is basically $1.5 \sim 2.5 \mathrm{~m} / \mathrm{s}$ on average. The boundary conditions are shown in Table 2.

Table 2. Boundary Condition

\begin{tabular}{cc}
\hline Analysis type & Steady state \\
\hline Turbulent model & SST model(Shear Stress Transport model) \\
Operating Temp. & $23^{\circ} \mathrm{C}$ (Ambient Temp.) \\
Working Fluid & Air \\
Gravity direction & - Y direction $(-\mathrm{g})$ \\
Inlet & $40 \mathrm{bar}, 240 \mathrm{bar}$ (Static Pressure) \\
Outlet & outlet / relative pressure 0 [bar] \\
\hline
\end{tabular}

No-slip conditions and impermeable conditions were placed on the walls of all solid bodies that come into contact with fluids. Since the analysis was intended to find out the pressure level inside the pipe when the fluid flows stably and the amounts of pressure drop according to the flows of the fluid, changes in the flow field over time were calculated assuming that the working fluid was air, which is an incompressible fluid. For flow analyses for the area inside the flow sensor, the heat of the flow sensor according to temperature/pressure was analyzed. The flow characteristics of the flow sensor under the operating temperature condition $\left(-20 \sim 60^{\circ} \mathrm{C}\right)$ were reviewed. For flow analyses for the flow sensor according to working fluid, velocity distributions according to working fluids such as air and water were reviewed and calculated, temperature/pressure distributions according to working fluids were reviewed, and flow characteristics were derived. The results of such flow analyses were reviewed and reflected in the design. Analysis results are presented in Figure 3 as examples.

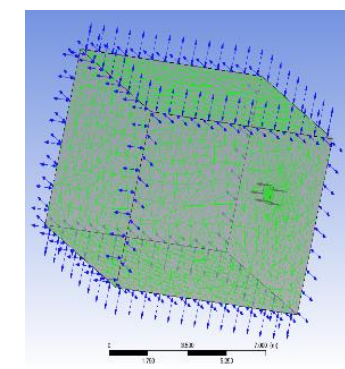

(a) Example of deriving the flow field

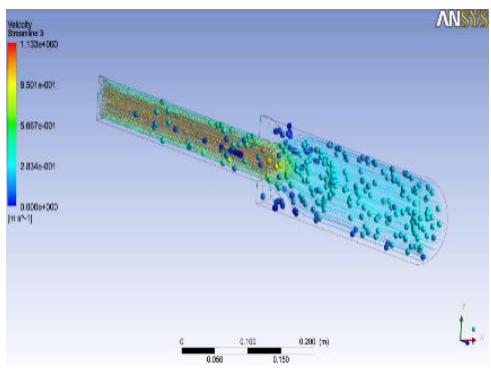

(b) Example of flow analysis result(Velocity Streamline)

Figure 3. Flow field derivation and flow analysis

The working fluid was limited to air. Air density is calculated based on temperature, pressure, and relative humidity. The pressure, temperature, and relative humidity are measured to calculate air density, and the unit of air density is $\mathrm{kg} / \mathrm{cm}^{3}$. 


\section{CONSTRUCTION OF THERMAL TYPE GAS FLOW SENSOR SYSTEM}

The thermal type gas flow sensor that will be developed with the present study can be installed on gas discharge lines in gas engines and gas power plants and implemented to detect gas flows and sound the alarm when the set value has been exceeded, and a system can be constructed so that the sensor can be protected from the risk of explosion. The sensor can be applied to environments where super-precision and safety are required as it can be used to stop the operation of peripheral equipment when an emergency has occurred or control flow rates.

Since the thermal type gas flow sensor developed through research can be said to be an important sensor that requires the explosion-proof function to withstand high pressure and the vibration-proofness and durability to withstand severe vibrations and poor surroundings because it can be installed on gas lines.

A view of the thermal type gas flow sensor applied to a gas pipe line in a gas engine as one of the targets to which the sensor can be applied is presented in Figure 4.

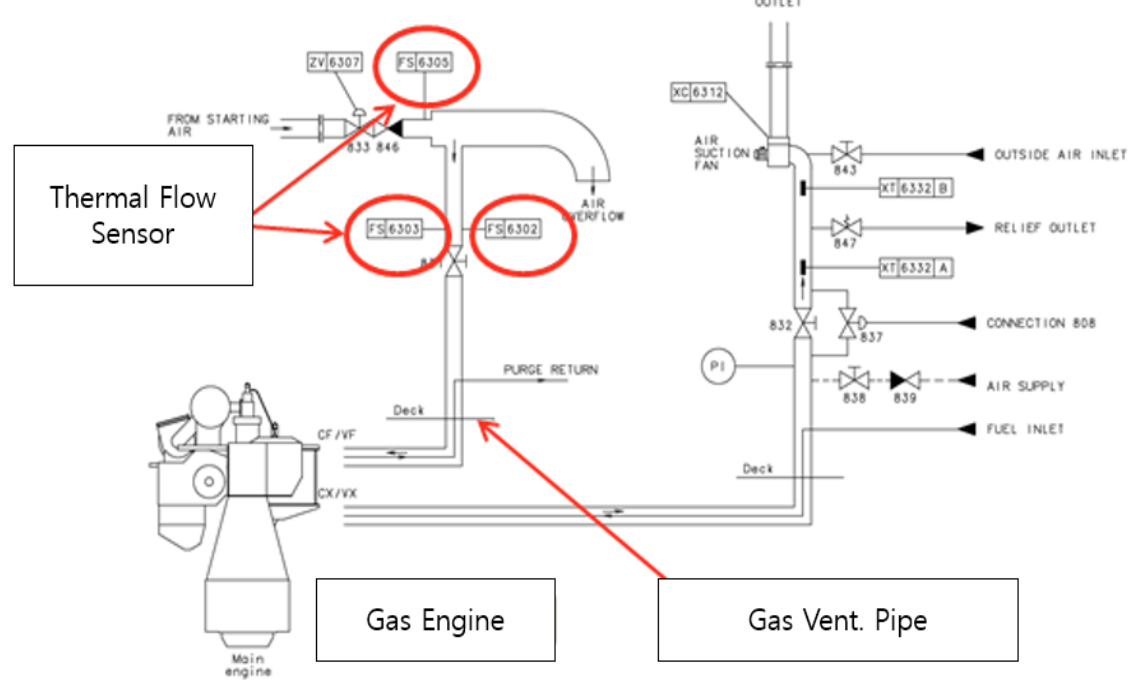

Figure 4. Applied to gas engine and gas pipe

The developed circuit consists of largely three parts: a sensing part, an amplifying part, and an output part. The power supply was designed with $24 \mathrm{~V}$ DC and an additional circuit for noise prevention was designed for signal accuracy. Other details were designed according to fluid types, sensor specifications, and output specifications. The PCB was designed so that heat can be sufficiently dissipated to maintain the temperature and environmental conditions of the installation site, and parts suitable for the environmental conditions were selected. In addition, a resonance circuit was designed considering the severe vibration conditions of vessels.

The performance of the substrate was tested to see if the designed output is generated when the element is attached to the substrate, and the test was conducted in diverse environments with different levels of vibration including no vibration, temperatures, and pressures to identify operating states. For commercialization, dustproof \& waterproof tests were conducted with IP66 dustproof \& waterproof grades.

Among the functions of individual parts of the developed sensor controller, the flow occurrence indication LED was designed to display two modes, a measurement mode and a standby mode. They were developed to display the operation states of the sensor module so that whether any flow has occurred and whether the device is currently on standby more is indicated by the LED according to the operation mode. The measurement mode was developed to display no flow, very low flow rates, and flow rates that exceed the reference value. The standby mode was implemented to cause the LED to flicker during normal operation. In the case of the control unit, the upper limit point adjustment unit was implemented so that the upper limit range of operation can be variably set. In particular, since the upper limit point should be adjusted while checking the set value through separate communication with the computer, the upper limit point adjustment unit was developed to prevent arbitrary manipulation of the upper limit point. The lower limit point adjustment unit was also implemented so that it can be adjusted by the user. The control unit was developed to set the reference point at which the flow rate is detected. The status LED was implemented to indicate the 
status of the operation. The relay connection unit was developed to connect an external lamp or buzzer so that it can be used as a terminal to indicate flow rates when flows occur. Diagram of module configuration of thermal type gas flow sensor shon in Figure 5. The thermal type gas flow sensor control module is presented in Figure 6.

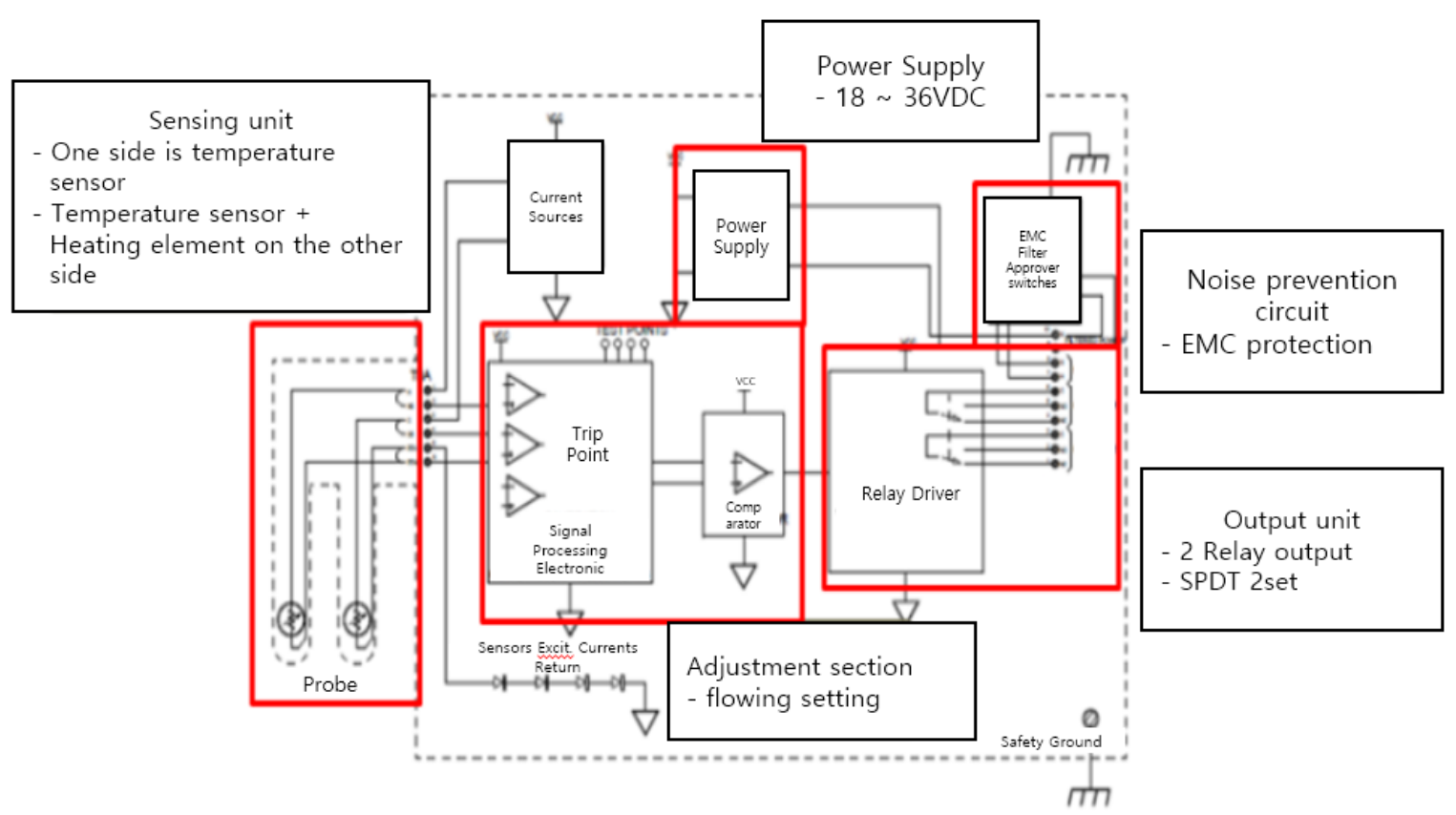

Figure 5. Diagram of module configuration of thermal type gas flow sensor

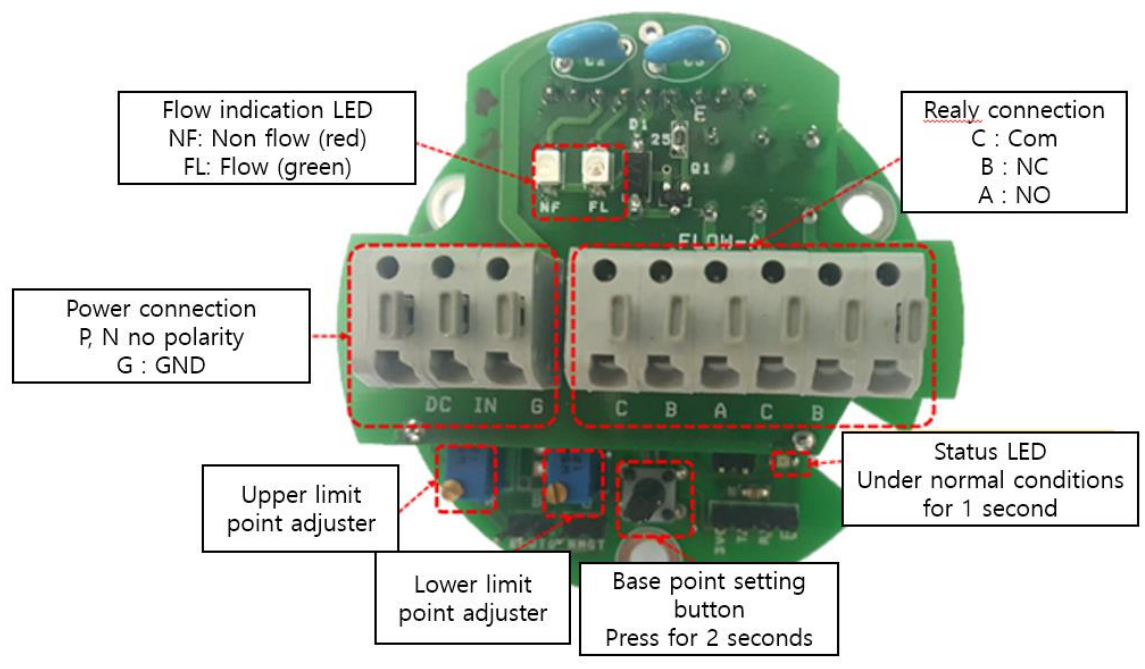

Figure 6. Thermal type gas flow sensor control module

\section{EXPERIMENTAL RESULTS AND ANALYSIS}

A system for experiments was constructed by constructing a pressure gauge, a thermal type flow sensor, and a pressure pump, as shown in Figure 7, and pressure experiments were conducted to measure the maximum pressure. 


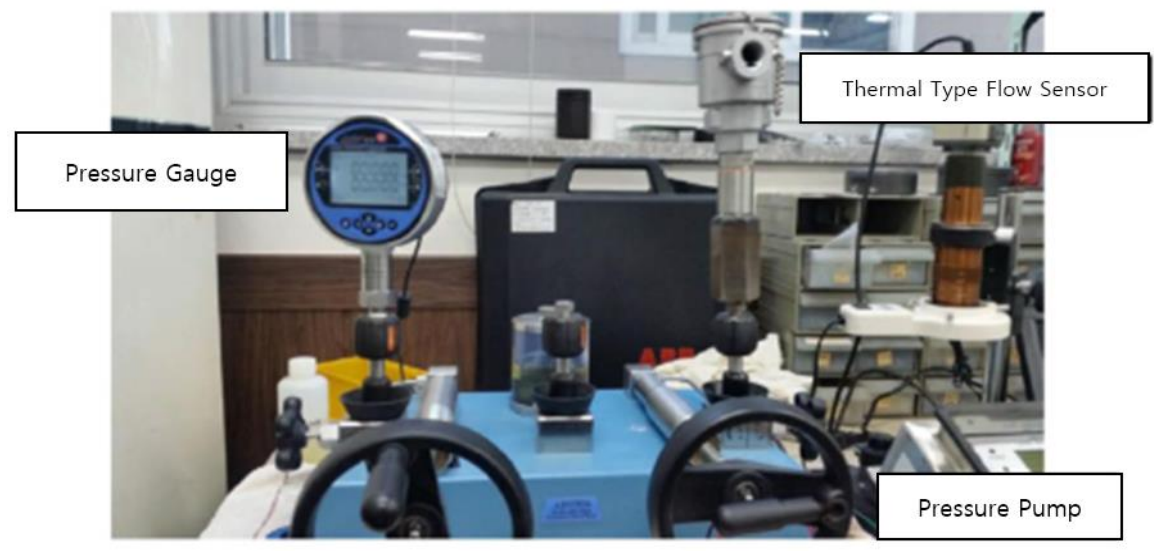

Figure 7. Maximum pressure test

Maximum pressure tests were carried out with a pressure not lower than 300 bar for 10 minutes, and the pressure did not change for 10 minutes. Therefore, the sensor module was evaluated to have sufficiently overcome 300 bar, thereby satisfying the condition that requires at least 240 bar, which was the development target value. From the experimental results it can be seen that a durable sensor module that satisfactorily withstands high pressures reaching 300 bar was developed. To measure the reaction time of the sensor module, a data recorder was constructed to build a system to record the output of the sensor module, as shown in Figure 8. The data recorder was implemented to display the data transmitted from the sensor and also display the time at which the data are transmitted using a clock inside the system.

As an experimental condition for measuring response time, the input pressure was set to 7 bar to measure the time taken to indicate "no flow" after fluid stops flowing through the data recorder. The no flow value was set to 136 , and the data recorder was set to recognize a state of no flow when the value dropped below the set value. According to the experiment results, the response time was $8 \mathrm{sec}$, indicating that the development target value of $10 \mathrm{sec}$. was satisfied.
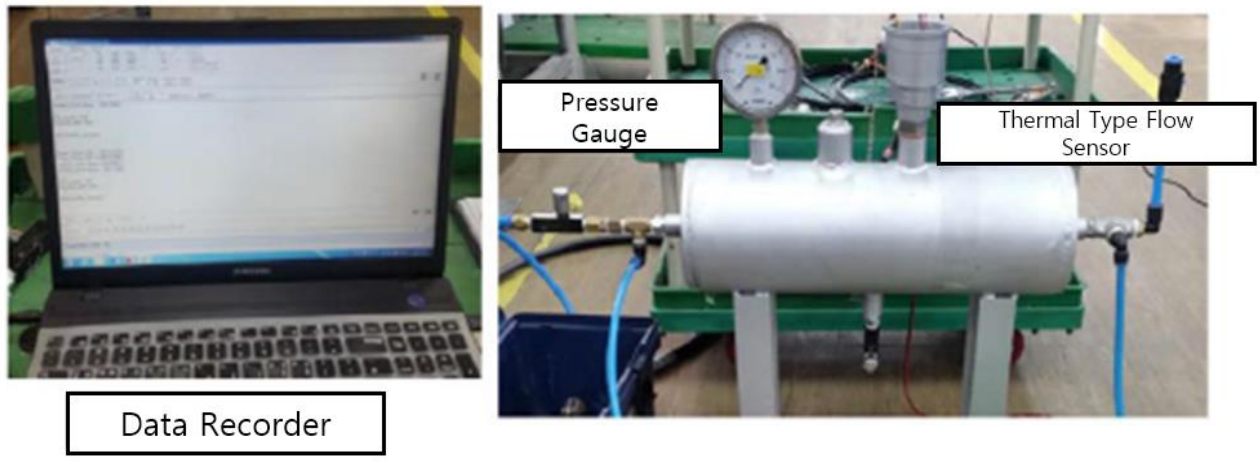

Figure 8. Response time measurement test

To test the repeatability, repeated experiments were conducted in the environment as shown in Figure 8 to measure whether errors were lower $1 \%$. As a test condition, the pressure was set to 7 bar and the response time to the fluid was repeatedly measured. The results of the experiments repeated three times were shown to be $0 \%$ in the first experiment, $0.06 \%$ in the second experiment, and $0.07 \%$ in the third experiment, so the sensor was evaluated to have achieved the target value of $1 \%$ or lower. To conduct pressure drop tests, a system to measure the differential pressure between the front and rear ends of the flow sensor with a differential pressure transmitter was constructed, as shown in Figure 9, and tests were conducted with an input pressure of 7 bar and a maintaining time of $10 \mathrm{~min}$. According to the test results, pressure differences of around 2.6 mbar occurred between the front and rear ends, indicating that the sensor achieved the development target value of 5 mbar or lower. 


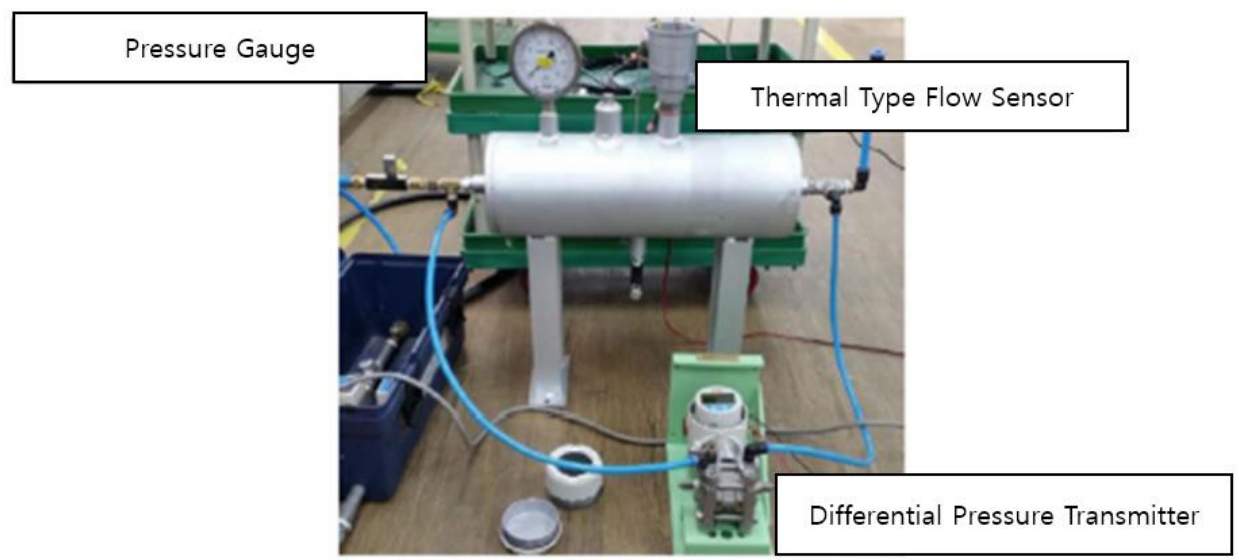

Figure 9. Pressure drop test

\section{CONCLUSION}

To verify the explosion-proof performance of the explosion-proof thermal type flow sensor, a pressure of 300 bar was applied to the inside of the sensor structure to conduct structure strength analysis, and as a result, it could be identified that the sensor cover and body and sensor unit were all structurally sound, as all of their safety factors exceeded 1, and that the developed product performed sufficiently in experiments. In the present study, it was confirmed that the explosion-proof thermal flow sensor applicable to gas engines for vessels can be localized and that explosion-proof flow sensors that can satisfy the specifications required by demanders can be developed. The developed product is expected to be able to replace the flow sensors for gas engines for vessels that have been supplied through imports.

\section{REFERENCES}

[1] K. C. Lee, C. W. Hur, Fabrication and characterization of a small-sized gas identification instrument for detecting $L P G / L N G$ and CO gases, International Journal of KIMICS, vol. 4, no. 1, pp. 18-22, 2006

[2] K. Lee, K. R. Ryu, C. W. Hur, Thick-film ammonia gas sensor with high sensitivity and excellent selectivity, International Journal of Marine Information and communication Sciences, vol. 2, no. 1, pp. 22-25, March 2004

[3] O. Lupan, G. Chai, L. Chow, Fabrication of $\mathrm{ZnO}$ nanorod-based hydrogen gas nanosensor, Microelectronics journal, vol.37, no.12, pp.1211 1216, 2007.

[4] P. Tardy, J. Coulon, C. Lucat, F. Menil, Dynamic thermal conductivity sensor for gas detection, Sensors and actuators", B. Chemical, vol.98, no.1, pp.63 68, 2004.

[5] M. Arndt, Micromachined thermal conductivity hydrogen detector for automotive applications, Proceedings of IEEE, no.2, pp.1571 1575, 2002.

[6] P. Bruschi, M. Piotto, G. Barillaro, Effects of gas type on the sensitivity and transition pressure of integrated thermal flow sensors, Sens. Actuators A, vol. 132, no. 1, pp. 182-187, 2006.

[7] A. Kularni, S. Patil, R. N. Karekar, R. C. Aiyer, Fabrication and characterization of innovative gas flow sensor, Sens. Actuators A, vol. 122, no. 2, pp. 231-234, 2005.

[8] G. Kaltsas, A. G. Nassiopoulou, Gas flow meter for application in medical equipment for respiratory control: study of the housing, Sens. Actuators A, vol. 110, no. 1-3, pp. 413-422.

[9] Glaninger, A., Wide Range Semiconductor Flow Sensors, vol. 85, no. 85, pp. 139-146, 2000 